\title{
Safe Completion of Laparoscopic Cholecystectomy and Its Conversion Rate in a Tertiary Care Hospital
}

\author{
Muhammad Shahid Farooq, ${ }^{1}$ Rabia Altaf, ${ }^{2}$ Ahmad Uzair Qureshi, ${ }^{3}$, Fatima Naumeri, ${ }^{4}$ Abrar Ashraf Ali ${ }^{5}$
}

\section{Abstract}

Objectives: Laparoscopic cholecystectomy is a very good and safe procedure for the removal of gall bladder. The objective of our study was to see the conversion rate of laparoscopic cholecystectomy in our unit. Methods: This is a retrospective descriptive study. We conducted this study on 167 patients who underwent gall bladder removal in our unit at a Public sector hospital of Lahore.

Results: Our study showed that $163(97.6 \%)$ out of 167 patients had safe complete laparoscopic cholecystectomy while $4(2.4 \%)$ had to be converted to open cholecystectomy. About $40 \%$ of the procedures completed by laparoscope were difficult. Approximately $98 \%$ were completed by consultants and $42 \%$ were

\footnotetext{
${ }^{1}$ Assistant Professor of Surgery, KEMU/ Mayo Hospital, Lahore

${ }^{2}$ Post Graduate Resident, Dept of Pathology

King Edward Medical University, Lahore

${ }^{3}$ Assistant Professor of Surgery, KEMU/ Mayo Hospital, Lahore

${ }^{4}$ Assistant Professor of Paeds Surgery, KEMU/ Mayo Hospital, Lahore

${ }^{5}$ Professor of Surgery, King Edward Medical University, Lahore
}

Date of Submission: 08-04-2017

Date of $1^{\text {st }}$ Revision Received: 15-04-2017

Date of $2^{\text {nd }}$ Revision Received: 05-06-2017

Date of Acceptance for Publication: 10-06-2017

Conflict of Interest: None

Funding Source: None

\section{Contribution}

All Authors have contributed in Study Design, Data Collection, Data Analysis, Data Interpretation, Manuscript Writing and Approval. safely performed by the senior registrars.

Conclusion: Gall bladder surgery can be safely completed with laparoscope with good team effort and self-awareness of team.

Keywords: Safe laparoscopic cholecystectomy, conversion rate, difficulty, team work.

\section{Introduction}

Laparoscopic cholecystectomy was the procedure introduced in late 80s when the surgeons felt the need for a minimally invasive technique since they were performing over 500,000 cases of gall bladder removal annually. ${ }^{1}$ This was a revolution in the history of gall bladder surgery. The laparoscopic cholecystectomy has now replaced the open cholecystectomy and because of increasing experience in laparoscopic surgery it has become a safe alternative to open surgery ${ }^{2}$ and lately a gold standard of care for gall bladder diseases. ${ }^{3}$ Keeping pace with the rest of the world, laparoscopic surgery for gall bladder has also become a gold standard in most of the centres in our country. With this, the number of surgeries performed with the laparoscope for gall bladder is on rise. This rise has not only increased the number of patients getting benefit from this modality but has also resulted in an increase in complications. The benefits include shorter hospital stay, decreased post-operative need of analgesics and almost invisible wound scars. ${ }^{4}$ There are however a range of complications associated with this procedure ranging from minor bile leaks to major duct and vascular injuries. At presents we have a minimal local data which is available to depict the difficult situations which a surgeon may come across during the laparoscopic cholecystectomy. This is also true as regards the conversion rates of this procedure in our local 
population. Keeping this in consideration we planned to present our data to address this paucity of evidence.

\section{Patients and Methods}

This is a retrospective descriptive study and involved analysis of patient's records and procedures. This study was conducted at South Surgical Ward, Mayo Hospital Lahore from May 2015 to Jan 2017. We reviewed the records of 167 patients who were operated with in a period of 22 months. The patients were in the age range of $18-80$ years. The mean age was $38 \pm$ 12.43 years. All of these patients were scheduled for laparoscopic cholecystectomy and underwent the laparoscopic surgery for gall bladder. We used four port laparoscopic cholecystectomy technique as a standard in our unit. ${ }^{5}$ After obtaining the informed consent involving a possibility of conversion to open cholecystectomy the surgeries were carried out. The surgery was divided into three categories like normal, difficult and laparoscopic converted to open cholecystectomy. Normal laparoscopic cholecystectomy was labelled when the operator did not encounter any adhesions and inflammatory process in the procedure. It was said to be difficult when the operating surgeon came across fibrous adhesions, mucocele, empyema, fistulous communication between gall bladder and surrounding viscera and anatomical variations. Converted laparoscopic cholecystectomy was when the operating surgeon was unable to complete the procedure due to adhesions, inflammatory or infective processes and variations in the Calot's triangle and had to resort to open cholecystectomy. The cholecystectomies were either performed by the Consultants or in their direct supervision. The SPSS 20 was used to analyse the data.

\section{Results}

Out of 167 patients operated, $66(40 \%)$ patients had difficult procedure and $101(60 \%)$ patients had normal surgery on them. Out of 66 patients who had difficult procedure $14(21 \%)$ patients were males and $53(79 \%)$ patients were females. Out of 101 patients who had normal laparoscopic cholecystectomy 11 (10.9\%) were males and $90(89.1 \%)$ were females.

Our population showed that the majority of patients who got operated were females (Figure 1). The maximum number of the patients were within age range of $30-50$ years with a mean age of $38 \pm 12.43$ (Figure2). When we look at the difficulty level, 101
$(60.5 \%)$ patients had normal cholecystectomy and 62 $(37.1 \%)$ had difficult surgery while in $4(2.4 \%)$ patients laparoscopic surgery was converted to open cholecystectomy. When we analyse the frequency of the difficult situations encountered (Table 1) at the time of surgery, fibrous adhesions with $24 \%(n=40)$ of cases top the list and range from moderate to severe adhesion.

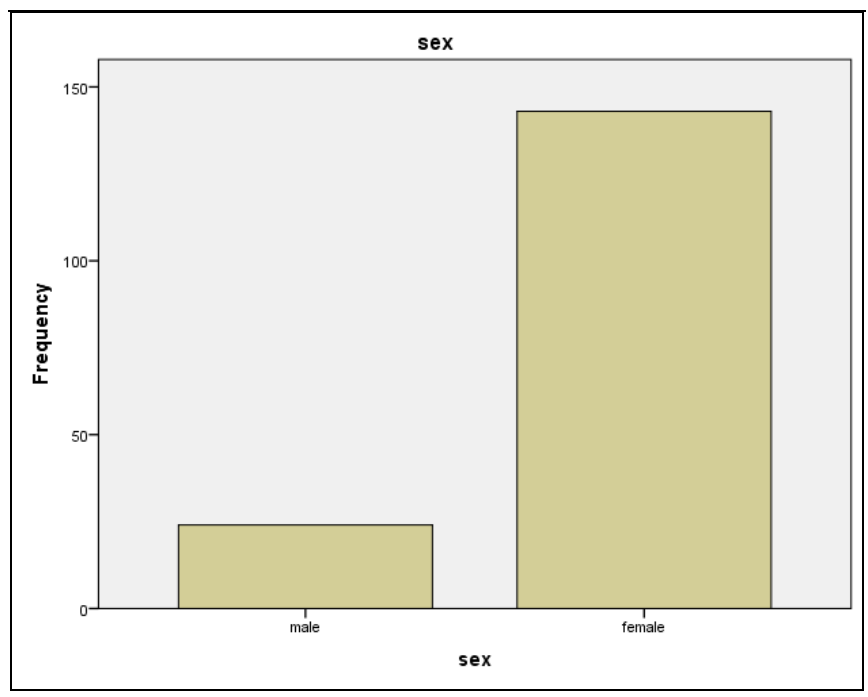

Fig. 1: Sex Distribution on LC Patients.

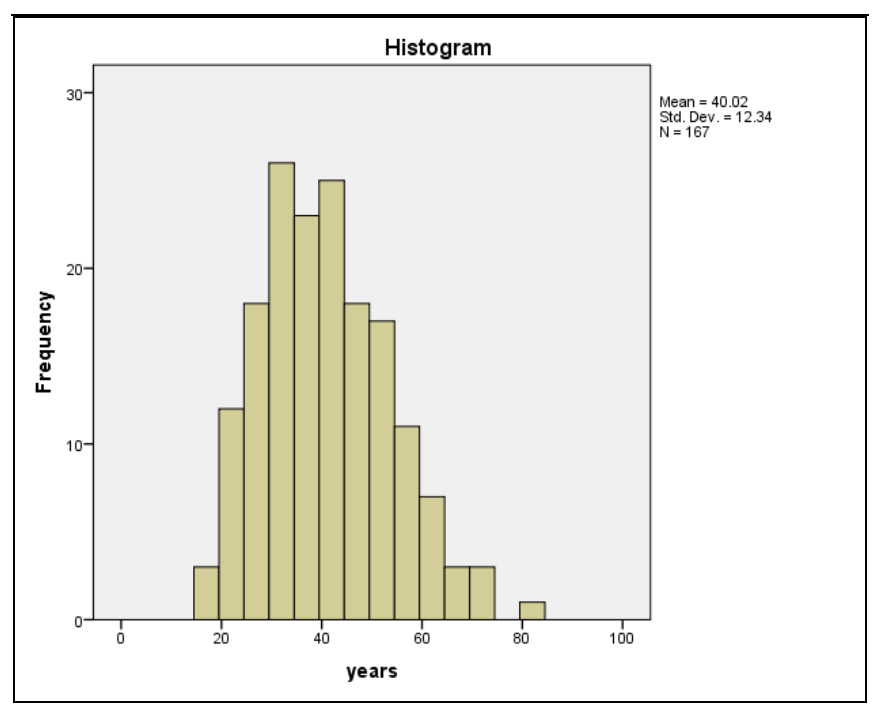

Fig. 2: Age Distribution of LC Patient.

The other common difficult situations were empyema and mucocele each comprising $4.8 \%(n=8)$ of the cases. Last of the list were anatomic variations in 
Table 1: Relationship of Surgeon with Normal and Difficult Situations.

\begin{tabular}{|l|c|c|c|c|c|c|c|}
\hline \multirow{2}{*}{ Surgeon } & \multicolumn{5}{c|}{ Difficult Situations Encountered } & \multirow{2}{*}{ Total } \\
\cline { 2 - 8 } & Normal & fibrous Adhesions & Empyema & Mucocele & Anomaly & Fistula & \\
\hline Consultant & 64 & 30 & 6 & 8 & 7 & 2 & 117 \\
\hline Senior Registrar & 22 & 6 & 1 & 0 & 1 & 1 & 31 \\
\hline Resident & 15 & 4 & 0 & 0 & 0 & 0 & 19 \\
\hline Total & 101 & 40 & 7 & 8 & 8 & 3 & 167 \\
\hline
\end{tabular}

$1.8 \%(n=3)$ of the cases. ${ }^{6}$

When we look at the conversion rate (Table

2) of our laparoscopic cholecystectomies, consultants had to convert $3(2.6 \%)$ cases to open cholecystectomy while senior registrars had to open 1 (3.2\%) patient out of 21 patients. The residents completed 19 surgeries successfully with the laparoscope.

The difficult situations ${ }^{7}$ which our team encountered while performing laparoscopic cholecystectomies were fibrous adhesions, infective process and anatomical variations in descending order.

\section{Discussion}

We had safely completed $163(97.6 \%)$ gall bladder surgeries with laparoscope out of 167 patients. ${ }^{8}$ The procedures with difficult situations make $40 \%$ of the whole group. Overall $2.4 \%(n=4)$ of the cases had to be converted ${ }^{9}$ to open for safe completion of gall baldder removal. This conversion rate is less than a similar series of 300 patients conducted at Social Security Teaching Hospital Islamabad where it was $7 \% .{ }^{10} \mathrm{~A}$ recent study from Israel shows a conversion rate of $5.8 \% .^{11}$ In another study by Kumar et.al from Utarpardesh India shows a conversion rate of $4.5 \%$ and another study from Palpa, Nepal shows a conversion rate of $6.9 \%$. $^{13}$ When we compared our conversion rate to the local and international literature we found that our conversion rate was far less than the local and international eviedence available. We may attribute our low conversion rate to our experienced and well trained team. Moreover our surgical team was well aware of its limitations and its need to call for help. The major difficulites were adhesion, infective process and anatomic variations of calots triangle with the least prevalence of fistulous communications between
Table 2: Relationship of Surgeon with Difficult Situation.

\begin{tabular}{|l|c|c|c|c|}
\hline \multirow{2}{*}{ Surgeon } & \multicolumn{3}{|c|}{ Finding } & \multirow{2}{*}{ Total } \\
\cline { 2 - 4 } & Normal & Difficult & Converted & \\
\hline Consultant & 65 & 49 & 3 & 117 \\
\hline Senior registrar & 21 & 9 & 1 & 31 \\
\hline Resident & 15 & 4 & 0 & 19 \\
\hline Total & 101 & 62 & 4 & 167 \\
\hline
\end{tabular}

the gall bladder and surrounding viscera. The most common fistulae were cholecystogartic, cholecystoduodenal and cholecystocolic fistulae. ${ }^{14}$ Most of the times the difficult situation at cholecystectomy was encountered by the consultant surgeons and this was about $44 \%$ of the cases. ${ }^{15}$ The consultants had to convert $2.6 \%$ of the cases to open surgery for safe completion of gall bladder removal. The difficult situations encountered by the senior registrars were in around $42 \%$ of the cholecystectomies and their conversion rate was $3.2 \%(\mathrm{n}=1)$. The conversion rate of senior registrars is higher than the consultants, even then the collective conversion rate of our unit is $2.4 \%$.

The significant factor which helped us to complete laparascopic surgery of patients safely with a low conversion rate was the awareness of our team for the need of help. ${ }^{16}$ Our surgeons when encountered difficult situation, which was beyond their competence, in safely completing the procedure called for help. Whoever from the surgical team was available either a senior colleague or a colleague with same level of competence helped the operating surgeon or even took over the procedure to complete it safely. The only disadvantage of this procedure was the longer operative time. When we look at the long operative time in lieu of safe completion of the procedure, it carried an insignificant 
value. The limitation which we could see in our study was that we did not use any assessment criteria to guage the difficult situation at cholecystectomy. The use of assessment criteria for guaging the difficulty level may be used in future to conduct a more robust study and this may add a useful evidence to the literature.

\section{Conclusions}

The safe completion and minimum conversion rate for the laparoscopic cholecystectomy is the result of awareness of our team of its competence and need to call for help. Above all a good team work is key to success in performing safe laparoscopic surgery. We must develop ${ }^{17}$ or follow some pre-operative screening system to predict the difficulties which a srugeon may come across while performing laparoscopic cholecystectomy. This will help us predict the difficult situation and manage our patients even more safely.

\section{References}

1. Olsen DO. Laparoscopic cholecystectomy. The American Journal of Surgery, 1991; 161 (3): 339-44.

2. Litwin DEM, Cahan MA. Laparoscopic Cholecystectomy. Surgical Clinics of North America, 2008; 88 (6): 1295-313.

3. Kumar V, Dadhwal US. Cholecystectomy: What's new? Medical Journal Armed Forces India, 2012; 68 (3): 288-92.

4. Bailey RW, Zucker KA, Flowers JL, Scovill WA, Graham SM, Imbembo AL. Laparoscopic cholecystectomy. Experience with 375 consecutive patients. Annals of surgery, 1991; 214 (4): 531.

5. Trichak S. Three-port vs standard four-port laparoscopic cholecystectomy. Surgical endoscopy, 2003; 17 (9): 1434-6.

6. Menon A. A comprehensive review of the factors predicting technical difficulty in laparoscopic cholecystectomy. International Surgery Journal, 2017; 4 (4): 1147-53.

7. Kala S, Verma S, Dutta G. Difficult situations in lapa- roscopic cholecystectomy: a multicentric retrospective study. Surgical Laparoscopy Endoscopy \& Percutaneous Techniques, 2014; 24 (6): 484-7.

8. Raju KSP, Naik KCT. Keywords Laparoscopy, Open Surgery, Cholecystectomy, Gall Bladder, Complications. A Retrospective Clinical Study of Laparoscopic and Open Surgery for Cholecystectomy Procedure, 2017 (95815).

9. Malik AM. Difficult laparoscopic cholecystectomies. Is conversion a sensible option. J Pak Med Assoc. 2015; 65 (7): 698-700.

10. Rashid T, Naheed A, Farooq U, Iqbal M, Barakat N. Conversion of laparoscopic cholecystectomy into open cholecystectomy: An experience in 300 cases. Journal of Ayub Medical College Abbottabad, 2016; 28 (1): 116-9.

11. Yuval JB, Mizrahi I, Mazeh H, Weiss DJ, Almogy G, Bala M, et al. Delayed Laparoscopic Cholecystectomy for Acute Calculous Cholecystitis: Is it Time for a Change? World Journal of Surgery, 2017: 1-7.

12. Kumar A, Singh KV, Shakya JPS, Sahu S, Dhiman S, Agrawal N. Prediction of difficulties during laparoscopic cholecystectomy by preoperative clinical examination and ultrasonography, 2017. 2017; 4 (4): 6.

13. Shrestha AL, Shrestha P, Brown D. Can Laparoscopic Cholecystectomy be a Feasible Standard in a Rural set up too? - An Experience of 348 cases from a Peripheral set up of Western Nepal. 2017. 2017; 13 (2): 4.

14. Correia MF, Amonkar DP, Nayak SV, Menezes J-LA. Cholecystocolic fistula: A diagnostic enigma. Saudi Journal of Gastroenterology, 2009; 15 (1): 42.

15. Malik A, Laghari AA, Talpur KAH, Memon A, Mallah Q, Memon JM. Laparoscopic cholecystectomy in empyema of gall bladder: An experience at Liaquat University Hospital, Jamshoro, Pakistan. Journal of Minimal Access Surgery, 2007; 3 (2): 52-6.

16. Ali A, Saeed S, Khwaja R, Samnani SS, Farid FN. Difficulties in Laparoscopic Cholecystectomy: Conversion Versus Surgeon's Failure. Journal of Ayub Medical College Abbottabad, 2016; 28 (4): 669-71.

17. Narwade N, Shaikh T, Jain R, Khan N, Ghosalkar M, Ansari S, et al. The study of laparoscopic cholecystectomy and its conversion to open cholecystectomy: analysis of 100 cases in Navi Mumbai, India. International Journal of Research in Medical Sciences, 2017; 3 (12): 3586-90. 